\title{
Somatosensation assessment using the NIH Toolbox
}

Winnie Dunn, PhD

James W. Griffith, PhD

M. Tracy Morrison,

OTD, R/L

Jennifer Tanquary

Dory Sabata, OTD,

OTR, SCEM

David Victorson, PhD

Leeanne M. Carey, PhD

Richard C. Gershon, PhD

Correspondence to

Dr. Dunn:

wdunn@kumc.edu

\section{ABSTRACT}

Touch sensation is one element of sensory function. As such, somatosensation is one of the sensory domains included in the $\mathrm{NIH}$ Toolbox, which is an assessment battery for measuring a range of human functions including emotional health, sensation, cognition, and motor function. We evaluated a variety of methods for inclusion in the NIH Toolbox main battery. In a convenience sample of 409 participants, we evaluated aspects of kinesthesia, pain, and tactile discrimination. We present results on these measures across the lifespan and discuss implications for future studies that use the NIH Toolbox and these measures. Neurology ${ }^{\circledR}$ 2013;80 (Suppl 3):S41-S44

\section{GLOSSARY}

ICC $=$ intraclass correlation coefficient.

Touch sensations contribute to somatic aspects of body scheme as a basis for interacting with the environment. ${ }^{1}$ Somatosensation includes responses to touch, pressure, temperature, and changes in movement related to the skin and joints. ${ }^{2,3}$ After a series of meetings, a team of consultants to the NIH Toolbox with expertise in somatosensation defined the construct to include the following.

Somatosensory function refers to the detection, discrimination, and recognition of body sensations. Somatosensation includes submodalities of touch sensation such as light touch, vibration, firm pressure and texture discrimination, proprioception involving sensing the location and movement of body parts, temperature sensation, and pain. For the NIH Toolbox, the term "somatosensation" will refer to all aspects of touch and proprioception that contribute to a person's awareness of his or her body parts and the direct interface of these with objects and the environment. The experience of sensing often involves a more complex integration of somatosensory inputs and may be influenced by emotional and social contexts.

Somatosensation is mediated, in part, by the somatosensory and posterior parietal cortices, which underlie the ability to identify tactile characteristics of surroundings, create meaning about sensations, and formulate body actions related to the sensations. ${ }^{4-6}$ Proprioception-based abilities include locating one's limbs without looking, directing a limb to a given point, and judging the weight of an object. ${ }^{7}$ The term kinesthesia specifically refers to the ability to detect the movement and position of one's limb in space without vision. ${ }^{1}$ Somatosensory function changes over the lifespan and strongly affects functioning in everyday life. ${ }^{1,89}$ People in mid to late adulthood experience decreased sensitivity to light touch and texture discrimination compared with children, adolescents, and young adults. ${ }^{10-13}$ There are also age-related differences in cutaneous pain, ${ }^{14}$ vibration and warm temperature sense, ${ }^{15-17}$ and spatial acuity. ${ }^{18-20}$ Much of this decline over time is attributed to progressive change in the sensitivity of cutaneous receptor ${ }^{21}$ and has functional implications. ${ }^{22}$

Difficulties in tactile and proprioceptive discrimination can limit a person's spontaneous hand use and the ability to manipulate and grip objects, affecting quality of life and, perhaps more importantly, safety. ${ }^{23-25}$ Given the impact of somatosensation on function and its wide variation across individuals and across the lifespan, the NIH Toolbox aimed to include this domain as part of the battery to evaluate sensory function for use in epidemiologic and prospective studies.

From the University of Kansas Medical Center (W.D., M.T.M., J.T., D.S.), Kansas City, KS; Northwestern University (J.W.G., D.V., R.C.G.), Feinberg School of Medicine, Chicago, IL; National Stroke Research Institute (L.M.C.), Florey Institute of Neuroscience and Mental Health, Melbourne; and LaTrobe University (L.M.C.), Victoria, Australia.

Go to Neurology.org for full disclosures. Funding information and disclosures deemed relevant by the authors, if any, are provided at the end of the article. 
The somatosensation team reviewed the literature to identify measures that were brief and easy to administer, quantitative, inexpensive, and could discriminate range of performance in a general population over the lifespan. During a pretesting phase, we evaluated several prototype tests for potential inclusion. In a subsequent validation phase, we examined brief measures of touch with subjects across the lifespan. In this report, we present some brief results from the validation phase for somatosensory measures considered for inclusion in the NIH Toolbox for Neurological and Behavioral Function. We selected sensory functions that showed promise to be sensitive in a general population for further investigation: touch discrimination of the fingertips, awareness of limb position, and pain.

METHODS Participants and design. We studied a convenience sample of community-dwelling children and adults ( $\mathrm{N}=$ 409, ages 3-85 years). Our groups collected data from 6 occupational therapy program sites: University of Kansas, Ohio State University, University of Pittsburgh, Washington University, Thomas Jefferson University, and LaTrobe University/National Stroke Research Institute. Most participants were tested on a single occasion. We tested a subset of participants on 2 occasions to investigate test-retest reliability.

Measures of somatosensation. Kinesthesia. We examined kinesthesia (i.e., the Brief Kinesthesia Test) using a method based on the work of Ayres ${ }^{26}$ (1971) for testing children. We asked participants to

\section{Figure 1 Brief Kinesthesia Test-4-item version as a function of age}

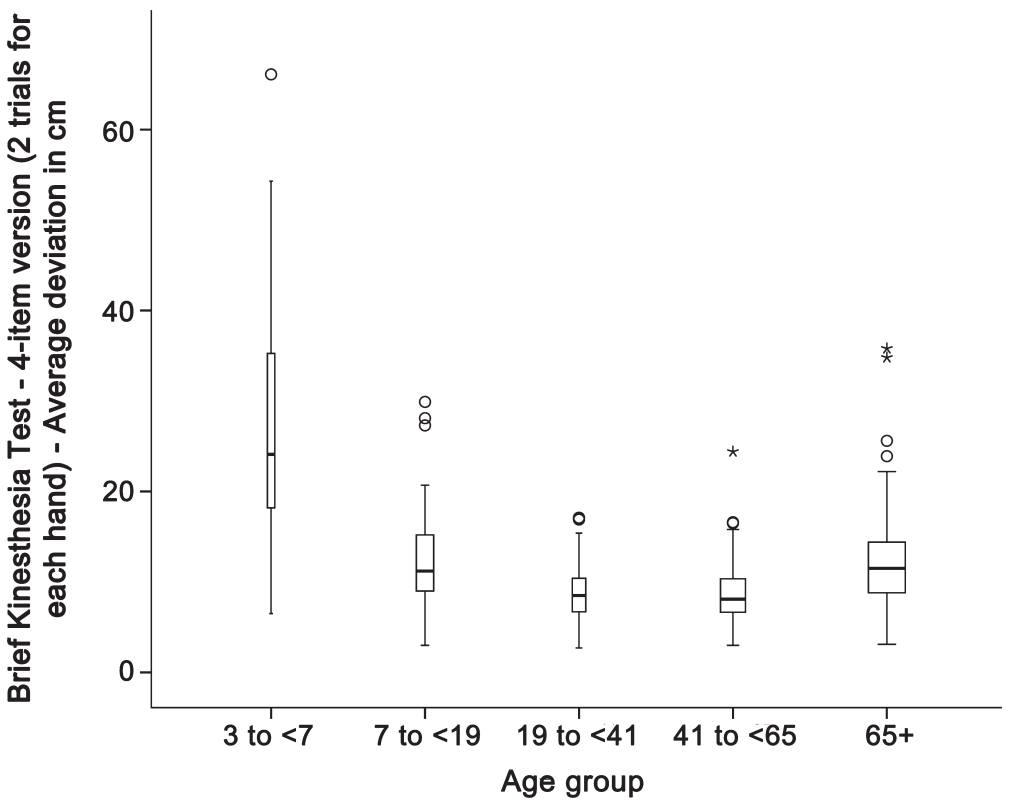

The score is the deviation from the target position measured in centimeters. The average score combines performance of the right and left hands. Higher scores indicate poorer performance. Age group is shown on the abscissa. Circles indicate possible outliers; asterisks indicate extreme cases. The width of the bars is proportional to sample size. reproduce movements without vision after being guided by the examiner. We measured the distance in centimeters from the response location to the target location. There were 3 items per hand (a short, medium, and long distance) for a total of 6 items.

Tactile discrimination. Tactile, or touch discrimination, is important in exploration of objects and performance of daily activities. ${ }^{8,25}$ Tactile discrimination can affect stereognosis, the ability to identify objects based on touch alone. ${ }^{1}$ A well-validated instrument, the Tactile Discrimination Test, ${ }^{27}$ uses standard surfaces for the stimuli. Discrimination is evaluated with a 3-alternative, forcedchoice design. ${ }^{28}$ The stimulus is a texture grating marked by ridges at set spatial intervals. Five different sets range from small to large differences. The texture gratings have been used in functional imaging studies of touch sensibility, with reproducible activation in primary and secondary somatosensory cortices among healthy volunteers. ${ }^{28}$ The test has normative standards, high test-retest reliability, and good discriminative test properties. ${ }^{29}$

Self-reported pain. We evaluated self-report (8 years to adulthood) and proxy-report (3-8 years) assessment for pain based on items from the NIH Patient Reported Outcomes Measurement Information System (see nihpromis.org); some of the items for adults will compose a supplement to the NIH Toolbox. Pain measures are discussed separately in this issue of Neurology ${ }^{\circledR}$ (see Cook et al.).

RESULTS Space does not permit a report of the findings from the validation phase for each measure; these will appear in other articles. Herein, we focus on 2 measures considered for the NIH Toolbox: the Brief Kinesthesia Test and a brief version of the Tactile Discrimination Test. ${ }^{29}$

Brief Kinesthesia Test. In the analysis, we used the medium and long distances only for both hands (4 items) to shorten testing time and because the short items did not contribute to the best-fitting model. Confirmatory factor analysis of the 4-item version yielded an acceptable fit for a 1-factor model (comparative fit index $=0.97$, Tucker-Lewis index $=0.90$, root mean square error of approximation $=0.098,90 \%$ confidence interval for root mean square error of approximation $=0.04$ 0.17 , standardized root mean square residual $=0.028$ ) $(\mathrm{n}=367)$. Figure 1 presents a boxplot of scores as a function of age. The $U$ shape in the figure suggests that performance was best for individuals in the middle of the age distribution. Analysis of variance, using 5 age groups based on previous literature ${ }^{30}$ (figure 1), supported significant differences among the groups: $F_{4,358}=74.92$, $p=0.000$. Follow-up contrasts on adjacent age groups were also significant, except for those aged 19 to 40 years vs those 41 to 65 years. These 2 groups were not different from each other $(p=0.946)$. This finding is consistent with studies of children that show an age trend of increasing accuracy from younger to older children. ${ }^{29}$ Test-retest reliability on a subsample $(n=26)$ was adequate for the 4-item version (intraclass correlation coefficient [ICC] $=$ $0.71)$. ICC was based on a 2 -way mixed model, single measures.

Tactile Discrimination Test. We tested a subset ( $\mathrm{n}=$ 189) of the total sample on a brief version of the 
Figure 2 Brief Tactile Discrimination Test performance by age

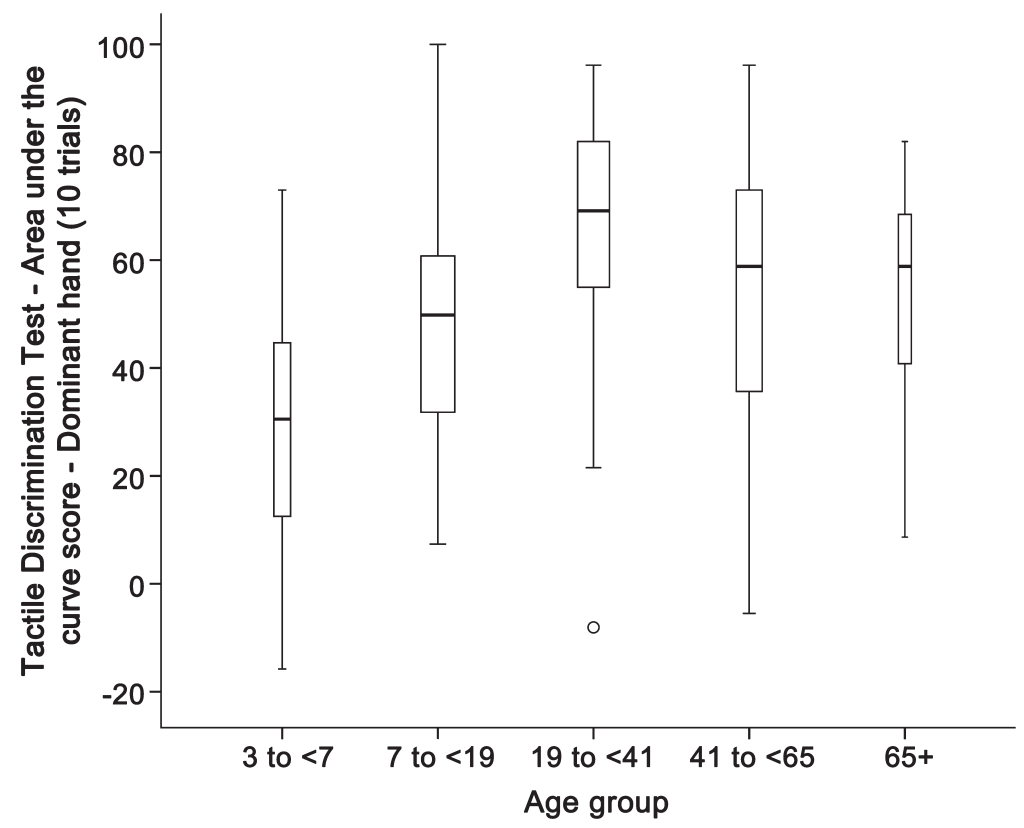

The score is an area-under-the-curve measure and compares a theoretical distribution of responses to chance performance. Higher scores indicate better performance. Age group is shown on the abscissa. Circles indicate possible outliers. The width of the bars is proportional to sample size. elderly individuals. ${ }^{28,31}$ The brief version of the Tactile Discrimination Test tested in this study showed a curvilinear relationship with age and there was large variability within each age category. This relationship is also consistent with past findings in children and adults. ${ }^{20,30,32}$ Children 6 years and younger demonstrated relatively poor performance, with some showing performance less than chance. This may be attributable, at least in part, to difficulty following test procedures at this preschool age. Field notes from examiners often noted poor concentration on the task, so cognitive issues may be confounding poor performance among the youngest children tested. Performance scores tended to be higher in the 20- to 40-year-old age bracket, as expected, ${ }^{30}$ with some evidence of deterioration in middle aged and older adults, consistent with evidence of reduced tactile thresholds with age..$^{20,30,32}$ Psychometrically, the reliability of the brief measure would be improved with more trials, as demonstrated for the original test version. ${ }^{29}$ The brief somatosensory measures demonstrated ability to identify differences in somatosensory skills across the lifespan, as expected from prior literature, and will potentially allow for efficient and effective measurement of one's sense of touch and kinesthetic awareness. It is recommended that researchers from different research areas include these measures in future studies to determine the possible contributions of somatosensation to a wide range of conditions.

\section{AUTHOR CONTRIBUTIONS}

Dr. Dunn: study concept and design, drafting, revising manuscript, analysis and interpretation of data, acquisition of data, study supervision. Dr. Griffith: study concept and design, drafting, revising manuscript, analysis and interpretation of data. Dr. Morrison: acquisition of data, revising manuscript. Ms. Tanquary: analysis and interpretation of data, study coordination. Dr. Sabata: study coordination, drafting, revising manuscript. Dr. Victorson: study concept or design. Dr. Carey: drafting/revising the manuscript, analysis and interpretation of data, acquisition of data. Dr. Gershon: revising manuscript, obtaining funding, overseeing project.

\section{STUDY FUNDING}

This study is funded in whole or in part with Federal funds from the Blueprint for Neuroscience Research, NIH, under contract no. HHSN-260-2006-00007-C.

\section{DISCLOSURE}

W. Dunn is the author of the Sensory Profile measures, which are published by Pearson Inc. Pearson Inc. owns the copyright on these tests, and Dr. Dunn receives a royalty when they are sold. J. Griffith has received financial support from NorthShore University HealthSystem, the Cleveland Clinic Foundation/Teva Neurosciences, Inc., Ironwood Pharmaceuticals, Inc., Forest Laboratories, Inc., the NIH, the Department of Defense-United States Army, and the FWO, Belgium. In addition to NIH Toolbox funding, he receives funding from the NIH for other research (grant U01 DK082342). He has also been a paid consultant to Dr. Kathryn Grant of DePaul University, and maintains a clinical psychology practice for which he bills for his services. T. Morrison, J. Tanquary, and D. Sabata report no disclosures. D. Victorson holds stock options in Eli Lily and Company, received an honoraria for serving on the Steering Committee of the Reeve Neuro-Recovery Network, was funded by NIH contracts HHSN265200423601C and HHS-N-2602006-00007-C and grants R01HD054569-02NIDRR, 1U01NS056975-01, 
and R01 CA104883, received support from the American Cancer Society (national and Illinois Division) for research in prostate cancer, received institutional support from NorthShore University HealthCare System for research in prostate cancer, received institutional support from the Medical University of South Carolina for sarcoidosis research, and received institutional support from the Northwestern Medical Faculty Foundation for urology research. L. Carey is supported by an Australian Research Council Future Fellowship (no. FT0992299) and was previously supported by a National Health and Medical Research Council of Australia Career Development Award (no. 307905). Dr. Carey is an expert consultant for the NIH Toolbox Project. R. Gershon has received personal compensation for activities as a speaker and consultant with Sylvan Learning, Rockman, and the American Board of Podiatric Surgery. He has several grants awarded by NIH: N01-AG-60007, 1U5AR057943-01, HHSN260200600007, 1U01DK082342-01, AG-260-06-01, HD05469; NINDS: U01 NS 056975 02; NHLBI K23: K23HL085766; NIA: 1RC2AG036498-01; NIDRR: H133B090024; and OppNet: N01-AG-6-0007. Go to Neurology.org for full disclosures.

\section{EDITOR'S NOTE}

The somatosensation instruments are available as experimental instruments and are not included in the final NIH Toolbox core batteries.

Received June 6, 2012. Accepted in final form October 30, 2012.

\section{REFERENCES}

1. Dunn W. Implementing neuroscience principles to support habilitation and recovery. In: Christiansen C, Baum CM, editors. Occupational Therapy: Enabling Function and Well-being. Thorofare, NJ: SLACK; 1997:182-223.

2. Lumpkin EA, Bautista DM. Feeling the pressure in mammalian somatosensation. Curr Opin Neurobiol 2005;15: 382-388.

3. Puce A, Carey L. Somatosensory function. In: Weiner IB, Craighead WE, editors. The Corsini Encyclopedia of Psychology. New York: John Wiley \& Sons; 2010:1678-1680.

4. Romo R, Hernández A, Salinas E, et al. From sensation to action. Behav Brain Res 2002;135:105-118.

5. Luna R, Hernandez A, Brody CD, Romo R. Neural codes for perceptual discrimination in primary somatosensory cortex. Nat Neurosci 2005;8:1210.

6. Tsunozaki M, Bautista DM. Mammalian somatosensory mechanotransduction. Curr Opin Neurobiol 2009;19:362-369.

7. Bear MF, Conners BW, Paradiso MA. Neuroscience: Exploring the Brain. Baltimore: Williams \& Wilkins; 1996.

8. Carey LM. Loss of somatic sensation. In: Selzer ME, Clarke S, Cohen L, Duncan P, Gage FH, editors. Textbook of Neural Repair and Rehabilitation. New York: Cambridge University Press; 2006:231-247.

9. Shaffer SW, Harrison AL. Perspective - aging of the somatosensory system: a translational perspective. Phys Ther 2007;87:193-207.

10. Bruce MF. The relation of tactile thresholds to histology in the fingers of elderly people. J Neurol Neurosurg Psychiatry 1980;43:730-734.

11. Humes LE, Busey TA, Craig JC, Kewley-Port D. The effects of age on sensory thresholds and temporal gap detection in hearing, vision, and touch. Atten Percept Psychophys 2009;71:860-871.

12. Legge GE, Madison C, Vaughn BN, Cheong AMY Miller JC. Retention of high tactile acuity throughout the life span in blindness. Percept Psychophys 2008;70:1471-1488.
13. Thornbury JM, Mistretta CM. Tactile sensitivity as a function of age. J Gerontol 1981;36:34-39.

14. Gibson S, Gorman MM, Helme RD. Assessment of pain in the elderly using event-related cerebral potentials. In: Bond MR, Charlton JE, Woolf CJ, editors. Proceeding of the Sixth World Congress on Pain. Amsterdam: Elsevier; 1991:527-533.

15. Gescheider GA, Beiles EJ, Checkosky CM, Bolanowski SJ, Verrillo RT. The effects of aging on information-processing channels in the sense of touch: II. Temporal summation in the P channel. Somatosens Mot Res 1994;11:359-365.

16. Kenshalo DR Sr. Somesthetic sensitivity in young and elderly humans. J Gerontol 1986;41:732-742.

17. Sands ML, Schwartz AV, Brown BW, Nevitt MC, Seeley DG, Kelsey JL. Relationship of neurological function and age in older women: the study of osteoporotic fractures. Neuroepidemiology 1998;17:318-329.

18. Stevens JC. Aging and spatial acuity of touch. J Gerontol 1992; $47: 35-40$.

19. Stevens JC, Choo KK. Spatial acuity of the body surface over the life span. Somatosens Mot Res 1996;13:153-166.

20. Stevens JC, Patterson MQ. Dimensions of spatial acuity in the touch sense: changes over the life span. Somatosens Mot Res 1995;12:29-47.

21. Nadler MA, Harrison LM, Stephens JA. Changes in cutaneomuscular reflex responses in relation to normal ageing in man. Exp Brain Res 2002;146:48-53.

22. Corriveau H, Hebert R, Ratche M, Prince F. Evaluation of postural stability in the elderly with stroke. Arch Phys Med Rehabil 2004;85:1095.

23. Blennerhassett JM, Carey LM, Matyas TA. Grip force regulation during pinch grip lifts under somatosensory guidance: comparison between people with stroke and healthy controls. Arch Phys Med Rehabil 2006;87:418-429.

24. Carey LM, Matyas TA, Oke LE. Sensory loss in stroke patients: effective training of tactile and proprioceptive discrimination. Arch Phys Med Rehabil 1993;74:602-611.

25. Carey LM. Somatosensory loss after stroke. Crit Rev Phys Rehabil Med 1995;7:51-91.

26. Ayres AJ. Characteristics of types of sensory integrative dysfunction. Am J Occup Ther 1971;25:329-334.

27. Ayres AJ. Sensory Integration and Praxis Tests, 3rd ed. Los Angeles: Western Psychological Services; 1996.

28. Carey LM, Abbott DF, Egan GF, Donnan GA. Reproducible activation in BA2, 1 and $3 \mathrm{~b}$ associated with texture discrimination in healthy volunteers over time. Neuroimage 2008;39:40-51.

29. Carey LM, Oke LE, Matyas TA. Impaired touch discrimination after stroke: a quantitative test. Neurorehabil Neural Repair 1997;11:219-232.

30. Wickremaratchi MM, Llewelyn JG. Effects of ageing on touch. Postgrad Med J 2006;82:301-304.

31. Kaplan FS, Nixon JE, Reitz M, Rindfleish L, Tucker J. Age-related changes in proprioception and sensation of joint position. Acta Orthop Scand 1985;56:72-74.

32. Kenshalo DR. Age changes in touch, vibration, temperature, kinesthesis and pain sensitivity. In: Birren JE, Schaie KW, editors. Handbook of the Psychology of Aging. New York: Van Nostrand Reinhold; 1977:562-579. 


\title{
Neurology
}

\author{
Somatosensation assessment using the NIH Toolbox \\ Winnie Dunn, James W. Griffith, M. Tracy Morrison, et al. \\ Neurology 2013;80;S41-S44 \\ DOI 10.1212/WNL.0b013e3182872c54
}

This information is current as of March 11, 2013

\section{Updated Information \& Services}

\section{References}

Citations

Subspecialty Collections

Permissions \& Licensing

\section{Reprints}

including high resolution figures, can be found at: http://n.neurology.org/content/80/11_Supplement_3/S41.full

This article cites 25 articles, 3 of which you can access for free at: http://n.neurology.org/content/80/11_Supplement_3/S41.full\#ref-list-1

This article has been cited by 2 HighWire-hosted articles: http://n.neurology.org/content/80/11_Supplement_3/S41.full\#\#otherarti cles

This article, along with others on similar topics, appears in the following collection(s):

Clinical neurology examination

http://n.neurology.org/cgi/collection/clinical_neurology_examination

Information about reproducing this article in parts (figures,tables) or in its entirety can be found online at:

http://www.neurology.org/about/about_the_journal\#permissions

Information about ordering reprints can be found online:

http://n.neurology.org/subscribers/advertise

Neurology ${ }^{\circledR}$ is the official journal of the American Academy of Neurology. Published continuously since 1951, it is now a weekly with 48 issues per year. Copyright @ 2013 American Academy of Neurology. All rights reserved. Print ISSN: 0028-3878. Online ISSN: 1526-632X.

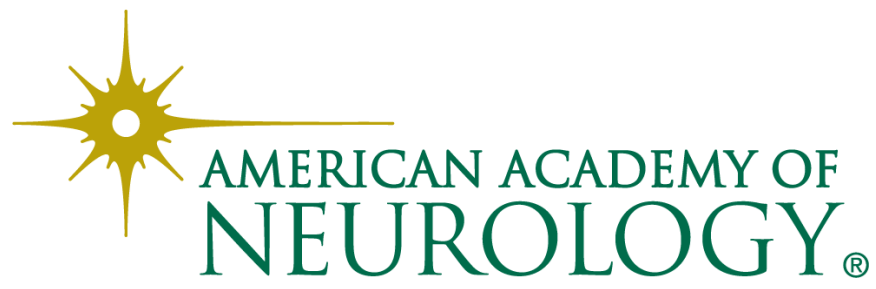

